\title{
Problems in the Cultivation of Youth Football Talents in Yanbian and the Countermeasures
}

\author{
Longhua Li \\ Yanbian University, Yanji Jilin, 133002, China
}

Keywords: Youth in Yanbian, Football talent cultivation issue, Coping strategy.

\begin{abstract}
There are still some problems in the process of cultivating young football talents in Yanbian, which is not able to guarantee the effect of work and make it difficult to conduct a comprehensive coordination and control over them. Therefore, teachers should develop a complete program of soccer talents training, carry out analytical work according to specific problems, take reasonable measures to deal with the problems, ensure that in football teaching, innovate teaching management forms, train students' football skills and make them master the operation Skills, improve their level of exercise.
\end{abstract}

\section{Introduction}

Yanbian is an ethnic minority area and should actively play its own traditional characteristics, in line with the requirements of national policies, promote the development of football culture, improve the educational environment, develop a comprehensive football talent training program, in the multi-dimensional environment during the construction of various content integration and coordination, in order to enhance the level of football talent training.

\section{Analysis on Problems of Training Youth Football Talents in Yanbian Area}

\subsection{Analysis of the main influencing factors}

In the process of actual development in Yanbian area, the cultivation of young football reserve talents is more important. However, due to environmental factors, problems that can not be solved often appear. First of all, for football schools, it can be divided into amateur and professional types. For the amateur type of school, although the amateur as the main content, but can create a special mechanism for the cultivation of football talent, and coaches wages and physical education funding, are allocated by the state funding, in a typical planned economic environment , Forming a good mechanism for personnel training. And the state has conducted a comprehensive management of amateur schools, developed a sound physical management programs, clear all aspects of the characteristics and requirements, to play a certain role in the work. However, during the development of market economy, there are still some problems in amateur institutions in football talent training system, which can not guarantee the educational effect. Second, during cultural knowledge education and sports training, contradictions often occur and it is difficult to conduct a comprehensive management of them. As a result, athletes' cultural attainments are deficient and their comprehensive development can not be promoted. Finally, in the process of fund management, due to the substantial increase in funding for sports schools, the adequacy of funds can not be guaranteed, problems that can not be solved during the exercise training can not be guaranteed, the actual development needs can not be met, and it is difficult to obtain good educational results.

\subsection{Analysis on the Problems of Football Talent Cultivation in Yanbian Area}

At present, there are still some problems in the process of cultivating young football talents in Yanbian. They failed to create a modern management mechanism and could not meet the job requirements. Yanbian area in 2000, when Aodong, Jilin Province will be into a B League, it was sold 
to Zhejiang Greentown, Yanbian, the number of young athletes gradually reduced, be affected to some extent. In the process of actual education, the influence of Yanbian youth soccer team is reduced. Under the influence of learning pressure, the effect of talent cultivation can not be guaranteed, and it is difficult to conduct a comprehensive coordination and control over it, seriously affecting the working level. During the football talent training, the specific problems are:

First, failure to establish a correct concept. Relevant departments failed to establish the correct concept of work during the training of young football talents, and did not reform and perfect the related training work. In actual work, the sports industry cannot be regarded as an important part, it is difficult to innovate the relevant training mechanism, and the relevant state departments and governments fail to carry out supervision and management and fail to create a modern education management mechanism. At the same time, in the process of actual education, the training channels are relatively backward. They can only focus on tactical training, cannot establish the correct concept for young athletes, and cannot create a modern management mechanism. Without overlooking the training of young football, education cannot be guaranteed Resource allocation effect, it is difficult to enhance the level of work, seriously affecting the reliability and effectiveness of young football talent training work.

Second, the problem of disengagement between training and league matches. In the process of youth football training, failed to integrate it with the league, not for the league requirements training content for young people, leading to the phenomenon of disjunction. Although young people can master the tactics of football, they lack practical experience and are prone to problems during the competition. At the same time, some athletes have low psychological quality and do not have the habit of teamwork. They cannot participate in competition activities better during the process of teamwork. As a result, the training of personnel is affected by all kinds of factors, resulting in one of the following progress and development the impact of the series.

Third, the popularity is low. During the soccer training for adolescents, national and social support is more important. However, due to the low level of generalization, there is a lack of support in all aspects of training. For example, there are few opportunities for the participation of the abroad mobilizers and there is no social support. At the same time, the football sport is impacted by the new sports. The traditional training methods cannot meet the needs of practical development. If we cannot innovate the training forms, the football training will be inhibited and cannot meet the actual development needs.

\section{Analysis on Measures Taken to Cultivate Youth Football Talents in Yanbian Area}

In the process of actual development in Yanbian, we should pay close attention to the cultivation of football talents, formulate a sound education program, establish a diversified management mechanism, clarify the requirements of all parties, establish a modern management mechanism, integrate educational resources, enhance work efficiency, Achieve the expected management purposes. Specific personnel training measures are as follows:

\subsection{Enhance the cultural quality of athletes}

During the period of talent cultivation, we should not only pay attention to the mastery of athletes' sports skills and tactics, but also enhance their cultural accomplishments so that they can better understand football contents and screen the best way of learning and exercising in the process of mastering cultural knowledge. First of all, we must strive for the support of parents and require parents to properly guide young people to learn cultural knowledge, enhance their cultural level and meet the current needs of talent cultivation in the process of family education. Secondly, under the environment of football training, a good cultural and educational atmosphere should be created for young people so that young people can acquire relevant knowledge of football and create a modern educational mechanism with the aim of enhancing their comprehensive literacy.

\subsection{Strive for relevant policy support}

At present, many parents in Yanbian area are reluctant to learn sports knowledge of their children 
and are afraid of affecting their children's entrance exams. Many young people go to school or their future career plans are determined by their parents and there is no inclination to participate in sports training. The main reason for such problems is that the government failed to formulate reasonable preferential policies for young people and could not meet the actual development needs. Therefore, in the process of actual progress, we should win the support of the government, establish perfect preferential policies for young athletes, gain the support of parents and ensure that we can create a good educational environment for young athletes. During this period, reform should be made in accordance with the policy of football coaches' configuration, employing highly qualified and experienced coaches to ensure the training of athletes in the actual training process. In addition, during the process of perfecting relevant policies, the state should conduct a reasonable analysis based on various aspects, clarify the purpose and requirements of coaches, strictly manage them, form a modern management and control mechanism and safeguard the good implementation of relevant work.

\subsection{Establish campus football mechanism}

In the process of training youth football talents in Yanbian, we need to create a campus soccer mechanism, all aspects of the strict management and control, to create a diversified talent training model. On the one hand, in campus teaching, according to the law of physical development of adolescents, we should make a reasonable choice of educational methods, formulate a sound education system for campus football, ensure the establishment of a modern talent cultivation mechanism and improve the education and teaching level. In the process of joint camp football teaching, all levels of education work should be guaranteed, a modern management system should be established, the good learning and progress of young soccer players should be maintained by scientific education, and the efficiency of personnel training should be guaranteed.

\subsection{Establish the correct concept for young people}

In the process of training young football talents, we need to establish a correct concept for them so that they can fully understand the importance of football learning in the daily study and life and master the relevant knowledge to lay the foundation for their own development. On the one hand, it is necessary to ensure the sustainable development of football training and mentally educate young people from the perspective of thinking so that they can form a correct understanding. On the other hand, it is necessary to analyze adolescent physical fitness, technical mastery and psychology, create a modern educational mechanism and incorporate advanced training methods to enhance the effectiveness of education and promote the healthy development of young people in football. In order to better cultivate football talents in Yanbian area, young people need to be educated in their ideology to make them view football correctly and increase their learning efforts. They should participate seriously in the training so as to accomplish their tasks better.

\subsection{Construction of high-quality coaches personnel}

In the process of training young football talents, we also need to build a team of highly qualified coaches, create a modern educational mechanism and clarify all requirements. First of all, the need to hire a higher quality professional coaches, requiring them to have a wealth of competition experience, to better carry out educational activities. For the coaches, it is the organizer during the football training and also the guide for the young people. It plays an important role in the related work. Therefore, we should pay enough attention to the goals and requirements of the coach coaches, Full control. Second, the trainers need to be trained with professional knowledge and advanced skills. The training of theoretical knowledge and advanced skills should be strengthened so that the trainers can grasp the theoretical knowledge of physiology and psychology in exercise so that they can guide them correctly during the actual training Athletes, the theoretical knowledge as the basic content, reasonable to carry out related teaching activities. At the same time, coaches should also accumulate rich experience in daily competitions and be able to use their competitions to guide young people to better participate in relevant training activities. Finally, in the process of training coach talents, we need to improve the management system, use incentives to stimulate their enthusiasm and ensure the 
effectiveness of work. For example: for the coaches to develop a sound system of responsibility, a clear job specific responsibilities, timely detection of the problems, take reasonable measures to solve the problem, in order to enhance coaches enthusiasm to meet the current actual development needs [2].

\subsection{Increase exchanges with western developed countries}

In order to formulate a sound training plan, we need to exchange ideas with the developed countries in the West and actively learn from advanced personnel training experience so that we can build a modern educational system for the development of football and enhance our work effectiveness. During this period, it is necessary to formulate a plan for exchange programs with developed western countries, establish and perfect a management system, clarify the objectives and requirements of all aspects of work, and conduct a comprehensive coordination and control over them. First of all, during the actual exchange, it is necessary to actively learn from the experience of young football talents cultivation in other countries and be able to innovate and train the system in a reasonable way. Secondly, in the process of international exchange, we should find out the problem of talent cultivation in time and take reasonable measures to solve the problem. Under the correct cognition, we should enhance the development of youth football education and promote the implementation of football talents cultivation in Yanbian. Finally, in the process of training qualified personnel, we need to formulate a sound system for input and output of qualified personnel, create an athlete selection mechanism and establish a correct concept. At the same time, to attract foreign high-quality trainers to the Yanbian area to cultivate young sports talents, we can comprehensively enhance the educational work level, create a modern management mechanism, coordinate the relations among all aspects of work, and ensure that education management can be strengthened [3].

\subsection{Connect training with the league}

In the traditional cultivation of Yanbian youth sports personnel, the relevant departments failed to link with the league, it is difficult to cultivate the practical ability of athletes, unable to enhance their psychological quality, resulting in all aspects of work affected. Therefore, in the process of actual training, the relevant departments should conduct a reasonable analysis of the contents of the league, create a wide range of personnel training mechanism that can provide opportunities for young people to compete in creating a good environment in the process of creating a modern training program, improve their work results. In order to ensure the level of personnel training, the relevant departments should also establish a modern tactical training mechanism that allows athletes to master the tactics at the competition site and cooperate with their teammates to create a good style of work and promote the good development of athletes in the process of teamwork, Accumulation of rich experience in the competition, a better participation in related activities [4].

\subsection{Complete management policies}

During the training of young football talents in Yanbian, the management system should be perfected, a modern management and control mechanism should be established, and various requirements should be clarified. First of all, it is necessary to formulate a sound management system according to the actual training characteristics of young athletes, make clear the concrete strategic goals and make the athletes form the correct cognition from objective aspects. Secondly, we need to innovate the training and education methods to stimulate the interest of athletes and enhance their enthusiasm, so that they can have fun in training and actively participate in relevant interactions. Finally, it is necessary to focus on the supervision and management work, in the dynamic mechanism of supervision and management, to ensure the effectiveness of education to meet the current needs of personnel training [5].

\section{Conclusions}

In the process of cultivating young football talents in Yanbian, the relevant departments should build up a contingent of highly qualified coaches, invest enough funds, win the support of parents, 
conduct overall coordination and control over all kinds of contents, summarize related work experience, and find out Existing problems, take reasonable measures to train qualified personnel.

\section{Acknowledgement}

Education Science "Thirteenth Five-Year Plan" of Jilin Province in 2017, Study on the development of school football in Yanbian and the cultivation model of youth football talents under the new situation, Number: GH170025.

\section{References}

[1] Jin Gangtie. Study on Cultivation Mode of Reserve Talents in Teenage Football School, Contemporary Sports Science and Technology, 2015,5(36):131-132.

[2] Jin Chunfeng. Practice and Exploration of Campus Football Development in China and South Korea, Yanbian University, 2016.

[3] Zhang Chengfeng, Han Siyin. A Comparative Study on Teenage Football Talent Cultivation System in China and Germany, Journal of Sports Adult Education, 2015, 31(1):26-29.

[4] Sun Yingnan. Research on Current Situation and Development Strategy of Youth Football Talent Cultivation in China, Jilin Institute of Physical Education, 2014.

[5] Han Erwei. A Study on the Diversified and Coordinated Development Strategy of Fostering Henan Reserve Talents, Henan University, 2014. 